\title{
VIDA Y MUNDO: REFLEXIÓN A PARTIR DE DILTHEY Y HUSSERL
}

\author{
Manuel Palacio ${ }^{1}$ \\ Universidad Santo Tomás
}

Recibido: marzo 14 de 2005

Aprobado: mayo 6 de 2005

\section{Resumen}

Tras la caída de los grandes sistemas idealistas, la reflexión filosófica se tornó hacia el problema metafísico fundamental que había dejado el idealismo: el problema de las relaciones del sujeto con el mundo. Las relaciones que se establecen entonces ya no son puramente epistemológicas sino que devienen en antropológicas y ontológicas. La dicotomía entre hombre y mundo se sintetiza en el concepto de vida como unidad estructural caracterizada por ser una conexión. En este orden de ideas, el problema fundamental es el de señalar las relaciones introspectivas de la misma estructura de la vida, es decir, analizar las relaciones entre vida y mundo a partir de los primeros filósofos que se ocuparon del tema, a saber, Dilthey y Husserl.

\section{Palabras clave}

Vida, mundo, Dilthey, Husserl, mundo de la vida, cosmovisión

\section{Abstract}

After the falling of the great idealist systems, the philosophical thought turned back to the essential metaphysical issue left by idealism: the problem of the relation between the subject and the world. The relations established are then not only episthemological but 
also anthropological and ontological. The disjunction between man and world is synthetized in the concept of life as a structural unit characterized as a relationship. In this order of ideas, the main problem is to indicate the introspective relations present in the structure of life, that is, to analize the relations between life and world from the first philosophers that undertook the theme, namely: Dilthey and Husserl.

\section{Key words}

Life, world, Dilthey, Husserl, lebenswelt, weltanschauung

De esta manera, el mundo es historicidad. Historicidad es vida. Luego el mundo es historicidad y vida.

Renato Cristin

La noción de mundo es algo que ha acompañado al hombre desde que existe sobre la tierra. No es difícil dar una definición popular y aceptada por la mayoría, pero sí lo es manejar teóricamente los problemas conceptuales de diversas disciplinas y ciencias con la concepción cotidiana. Por tal motivo, es necesario hacer una serie de precisiones al respecto. La vida se halla condicionada por la relación de un sujeto con el medio en el cual se encuentra ${ }^{2}$. Es decir, la vida siempre se encuentra situada en el mundo, aunque la significación de los elementos en el mundo se de en la vida. De esta manera surge el problema del presente ensayo: dilucidar las relaciones entre vida y mundo (entiéndase siempre vida humana) como fundamento de la vida predicativa.

\section{El mundo}

Kant consideró como un escándalo de la filosofía y en general de la razón hu- mana la inexistencia de una demostración suficiente frente a aquellos que habían tenido la ocurrencia de poner en duda la realidad del mundo ${ }^{3}$.

Lo que fue escándalo para Kant es una de las preguntas fundamentales de la época postidealista en el pensamiento alemán. El renacimiento de diversas formas de realismo, los esfuerzos de Dilthey e incluso del mismo Husserl, señalan la relevancia que tenía el problema por aquel entonces. La polémica entre las escuelas idealistas y realistas respecto a la pregunta por la existencia y preeminencia del mundo exterior sobre el sujeto que lo conoce se lleva varios estudios, como nos lo relata Dilthey en el texto de la cita anterior. Psicólogos, fisiólogos, filósofos, médicos, etc., están preocupados por el tema y formulan diversas posturas; sin embargo, la manera como intitula Dilthey su estudio es paradigmática y será la alternativa que se asuma en los ámbitos fenomenológicos, si bien por otros ca-

2 Wilhelm Dilthey, Teoría de la concepción del mundo (México: FCE, 1945) 16.

3 Wilhelm Dilthey, "Contribución al problema del origen y justificación de nuestra creencia en la realidad del mundo externo”, (1890), Crítica de la razón histórica (Barcelona: Península, 1986). 
minos. Dilthey nos habla de la creencia del mundo exterior, es decir, no pasa más allá de ser una creencia, $y$, sin embargo, ha servido para fundamentar todo lo que las ciencias, de la naturaleza y del espíritu, estudian ${ }^{4}$. ¿Cómo es esto? Observémoslo paso a paso.

Físicamente está primero el mundo. Las demostraciones racionalistas de la existencia del mundo (las de Descartes o Leibniz, por ejemplo) obedecen a un supuesto que considera que lo fundamental en el hombre es su razón, que la nota esencial del hombre es el pensamiento. Recordemos al respecto la ya famosa definición de pensar de Descartes, definición en que se incluye el sentir, el imaginar, el dudar, el querer, etc. Es decir, todo se ha reducido a pensamiento, que tiene su validez en la medida en que sea claro y distinto $^{5}$. El mundo para el racionalista es mera extensión, es algo vitalmente vacío, apenas configurado para solucionar el problema de la objetividad de las ideas, mas no para llevar una vida. Por el contrario, desde una perspectiva distinta como la nuestra, diremos que el mundo siempre está antes de mi vida, aunque sea en $m i$ vida en la que cobre significación. Así, no es necesario hacer una demostración del mundo exterior, en primer lugar porque la presencia del mundo no es conflictiva con nuestros supuestos, y en segundo lugar porque hacer una demostración del mundo es algo, en general, imposible ${ }^{6}$.

Expliquemos estos apartes un poco. A partir de la disolución del realismo antiguo y medieval, el paradigma moderno deviene en subjetivista; el problema de la primacía del sujeto es la posibilidad de salir de sí para reconocer que existe un mundo afuera. Lo que el realista da por supuesto se vuelve un con- flicto para el moderno. Por tal razón se enuncian, en la época moderna de la filosofía, las corrientes más diversas para explicar esas relaciones entre el sujeto y el mundo, entre el pensamiento y la extensión. Recordemos simplemente la teoría de la armonía preestablecida de Leibniz para señalar a qué grado de complejidad había llegado la especulación para solucionar el problema. Fundamentalmente, la existencia del mundo se veía explicada por el principio de causalidad, como lo hace Descartes e incluso Locke. El mundo, como mundo, se presenta pues de un modo mediato, ya no inmediato como para el realismo, lo que posee muchas implicaciones que iremos enunciando a lo largo de nuestro trabajo. Por otro lado, las consideraciones de que el mundo es siempre $m i$ mundo vienen de los avances que hicieran en sus respectivos estudios tanto Dilthey como Husserl y sus respectivos discípulos. No son otras las conclusiones de las formulaciones de las categorías de Weltanschauung y la de Lebenswelt.

Reconozcamos que aquella formulación del realismo tomista es acertada y pertinente: el mundo se muestra, no se demuestra. Como lo dice así mismo Dilthey:

(...) no tenemos ninguna "demostración” de la realidad de un mundo exterior, pues semejante demostración es, en general, imposible. Pero "se muestra" como situación empírica la coexistencia de un yo y de algo que le es exterior y ningún pensamiento puede ir más allá de esta situación empírica (...) siempre el mundo se halla presente para nosotros, en algún nivel (...) Nunca se nos da pura vida interior o puro mundo ex-

\footnotetext{
4 A este respecto remitimos al lector al texto de Husserl Experiencia y juicio (México: UNAM, 1980), especialmente a los parágrafos 7-10 de la introducción que hace el mismo Husserl.

5 Cf. René Descartes, Meditaciones metafísicas (Madrid: Espasa-Calpe, 1989) 125.

6 Cf. Dilthey, Teoría, 16.
} 
terior, los dos, no sólo están juntos sino vivamente intrincados $(\ldots)^{7}$.

E, incluso, el mismo Husserl dice: "El mundo como totalidad está ya siempre pre-dado pasivamente en la certeza, y genéticamente más originaria que la orientación a su conocimiento como totalidad es la que se dirige al ente particular, para conocerlo" ${ }^{\text {. Ambas }}$ consideraciones nos aportan principalmente dos ideas: la primera es que el mundo no es objeto de demostración, ya que está pre-dado y se asume como dado para toda praxis, sea de vida o de conocimiento, que en nuestro caso es lo mismo ${ }^{9}$; la segunda es que estas consideraciones, las de Dilthey y Husserl, son la antítesis de la concepción cartesiana del mundo como extensión y de la kantiana del mundo como idea. El mundo como extensión es lo más vacío, nos dice Husserl, y tiene razón, porque un mundo tal obedece a un paradigma del hombre como animal mecánico, mas no como persona que lleva una vida. El mundo de la vida es, pues, lo opuesto al mundo como extensión, como meras coordenadas en un plano que no en balde se denomina cartesiano. Respecto al mundo como idea reguladora, notamos cómo las posturas que manejamos, tomadas de Dilthey y Husserl, se oponen de manera contundente porque se asume que le mundo no es una construcción mental de tipo funcional para la reunión de fenómenos particulares, sino que es el horizonte y el correlato del sujeto que vive en él.

De esta manera, al mundo no se llega ni por causalidad, ni tampoco por síntesis de una pluralidad; la presencia del mundo exige que se crea en él; la evidencia del mundo es una creencia, una creencia que se supone y que configura el a priori de la correlación hombre-mundo, fundamento de los planteamientos que hasta ahora hemos enunciado y que formularemos más adelante. Dilthey, en el aparte de su Crítica de la razón histórica mencionado en la cita 2, indica de manera expresa cómo es que el mundo se presenta como creencia y qué sentido tiene dicha afirmación: “Todo el sentido de las palabras yo y otro, yo y mundo, distinción del yo frente al mundo externo, se halla en las experiencias de nuestra voluntad y en los sentimientos asociados a ellas”"10. Husserl, por otro lado, hace similares aseveraciones: "Conciencia del mundo es conciencia en el modo de la certeza de la creencia y no algo adquirido mediante un acto de asentar el ser"11.

Pero, ¿a dónde vamos con todo esto? Sencillo: nos dirigimos a establecer las relaciones entre vida y mundo, que, como veremos, no se trata de un mundo en abstracto, sino que se ve vitalizado por el dinamismo teleológico de la vida humana ${ }^{12}$. El mundo no es ya el mundo, sino que se vuelve mi mundo, en el sentido de que existe una apropiación de las condiciones de determinado mundo que lo hacen mundo-de-mi-vida. No por eso deja de existir el mundo fáctico, aquel que Husserl denomina mundo uno y que está regido por la causalidad. Al contrario, es ese mundo regido por la causalidad, determinista, estructurado bajo la espacialidad y la temporalidad, el que permite que el hombre lo dinamice para forjar el mundo de la vida, cuyo dinamismo proviene ahora de las mo-

Dilthey, Teoría ..., 16.

Husserl, Experiencia ..., 32.

Cf. Husserl, Experiencia ..., 31.

Dilthey, "Contribución ...", 173.

Husserl, "Experiencia ...”, 31.

Cf. Ernesto Mayz, La idea de "estructura psíquica” en Dilthey (Caracas: Universidad Central de Venezuela, 1949); y, en general, el pensamiento de Husserl. 
tivaciones humanas y no de las determinaciones naturales. Entonces, el mundo no lo podemos abarcar bajo la univocidad de un término que defina completa y cerradamente la configuración estructural del ser humano como ser-en-el-mundo. Así, pues, ¿cómo entender el mundo para establecerlo como el fundamento de la vida predicativa?

\section{Dilthey y el surgimiento de la cosmovisión}

Dilthey es reconocido por las dos grandes facetas de su trabajo: la introducción a las ciencias del espíritu y la teoría de las concepciones del mundo ${ }^{13}$. Sin embargo, tras todo el pensamiento de este filósofo se halla el descubrimiento de la idea de la vida, como dice Ortega y Gasset ${ }^{14}$.

El gran descubrimiento de Dilthey, que en nuestra época resulta un poco obvio pero que significó un gran avance en su momento, fue el de la correlación del hombre con la historia: el hombre mismo es historia. Pero la historia está compuesta de la vida, es decir, la vida es histórica. Sin embargo, no se trata de una vida ni de una historia en general, antes bien, se trata de la vida individual. Es como nos lo dice el profesor Renato Cristin: "Dilthey se opone a cualquier relativización del individuo a la historia universal. Lo infinito no es la historia sino la vida del individuo humano"15. Es decir, estamos presenciando una exposición de cómo es que en Dilthey la vida individual se instaura como base fundamental, se trata de una vida concreta, se trata de lo que hace la vida individualmente. Teniendo en cuenta estas aseveraciones podremos entender lo que este filósofo alemán nos quiere decir cuando expresa que "la vida crea desde cada individuo su propio mundo" ${ }^{16}$. Es decir, la vida va configurando su propia manera de estar en el mundo, a partir de lo que Husserl denominó retensiones y protensiones, lo cual también es aplicable a Dilthey, ya que manejan similar concepción de la estructura de la vida humana como conexión de vivencias, como flujo, torrente y río. Pero para responder a la inquietud que nos acomete, es preciso que nos hagamos una pregunta al respecto: ¿qué tipo de mundo es el que crea la vida? Indudablemente no estamos bajo paradigmas solipsistas; Dilthey mismo los ha rechazado $^{17}$, e incluso el profesor Cristin nos sugiere que en Dilthey el pensamiento de la intersubjetividad es uno de los fundamentos primordiales de su filosofía ${ }^{18}$. Pero seguimos sin responder el interrogante: ¿qué clase de mundo crea la vida?

La vida crea su propio mundo, es decir, no se trata de que cada ser humano tenga que crear nuevamente el mundo; lo que hace es crear su mundo particular, propio. Pero, más exactamente, lo que crea es su visión del mundo, una Weltanschauung, término que se ha traducido usualmente como cosmovisión, aunque preferimos la traducción de Imaz y Julián Marías para entenderla como concepción del mundo porque es evidentemente más

13 Cf. Eugenio Imaz, El pensamiento de Dilthey: Evolución y sistema (México: Colegio de México, 1946), cap. 10.

14 José Ortega y Gasset, “Guillermo Dilthey y la idea de la vida”, Obras completas, vol. VI (Madrid: Alianza/ Revista de Occidente, 1983).

15 Renato Cristin, Fenomenología de la historicidad: El problema de la historia en Dilthey y Husserl (Madrid: Ediciones Akal, 2000) 75.

16 Wilhelm Dilthey, Teoría de las concepciones del mundo (Barcelona: Altaya, 1994) 41.

17 Dilthey, “Contribución ...”, 147.

18 Cristin, Fenomenología ..., 70-71. 
amplia y diciente ${ }^{19}$. La vida crea entonces su propia concepción del mundo. Pero ¿qué es una concepción del mundo? “Concepción del mundo no es meramente un saber, sino que se manifiesta en valoraciones, conformación de la vida, destino, en la jerarquía vivida de los valores”20. Las explicaciones de Jaspers pueden llegar a diferir en puntos fundamentales con la de Dilthey respecto a las concepciones del mundo; sin embargo la aseveración que aquí citamos es pertinente, y Dilthey mismo la aprobaría, pues la concepción del mundo no es un simple acto intelectual, es toda una manera de ver el mundo, y por tanto de enfocar la vida en él. No entraremos aquí a señalar las clasificaciones de las concepciones del mundo con sus matices porque no es pertinente, y porque el mismo Dilthey las consideraba provisionales; además, las tres concepciones fundamentales, si bien engloban la humanidad (como concepto, no como especie), no la agotan, porque, como bien nos menciona Dilthey, "el conocimiento no agota lo real”21.

Es decir, la vida no se agota en lo que predicativamente se diga de ella, he aquí la primera pista de respuesta a nuestro trabajo. Todo el conocimiento reflexivo sobre nuestra vida no la agota. Pero la teoría de la concepción del mundo tiene un elemento fundamental que hemos obviado por un momento, y es lo que estábamos mencionando respecto al mundo, discurso que hemos de retomar.
Nos hemos dado cuenta de que tanto la reflexión de la vida como el mismo hecho de vivirla implica la presencia de un mundo, pero no de un mundo que lo sea de cosas, sino uno en que se vive, un mundo de importancias, diría Ortega y Gasset. Recordemos, el mundo se muestra, no se demuestra. Ese mostrar el mundo está fundado en una situación empírica, es decir que se muestra por medio de una situación en un medio que implique la experiencia. Si se conoce un poco la obra de Dilthey, es fácil darse cuenta de que él se está refiriendo a lo que él mismo denominó conciencia empírica y que define como la fusión de tres factores: el yo, las personas y las $\operatorname{cosas}^{22}$. Esta conciencia empírica es la que supera el problema del subjetivismo en el que el mundo se presenta como un problema. Una filosofía que parta de la vida asume que el mundo ya está dado, que hay un yo que vive (cualquier persona), junto con otros seres que también viven, en medio de cosas. Pero esto no es lo realmente importante, porque, aunque el mundo exista antes de la vida, es la vida la que, desde cada individuo, crea su propio mundo. No hay ningún tipo de solipsismo, como señalábamos anteriormente; por el contrario, es la expresión de que de un mundo dado se hacen diversas representaciones, diversas imágenes, diversas concepciones que obedecen más a un determinado ánimo que a una percepción diferente. El hecho es que ningún pensamiento pueda ir más allá de esa situación empírica.

19 Cabe aclarar que Eugenio Imaz en las traducciones que hace de Dilthey ha mencionado que si Dilthey hubiera escrito en español, habría utilizado la expresión concepto de la vida más que concepción del mundo (Cf. Dilthey, Teoría ... [1945] 93). Aunque tenemos en cuenta la acotación de Imaz, optamos por la expresión concepción del mundo, primero por la importancia del término mundo, y segundo porque consideramos que se puede manejar esta expresión con validez si se tiene en cuenta la mencionada aclaración.

20 Karl Jaspers, Psicología de las concepciones del mundo (Madrid: Gredos, 1967) 19.

21 Dilthey, Teoría ...(1994) 95. Cf. la nota 53, de Julián Marías, en la misma página.

22 Cf. Dilthey, Teoría ...(1994) 42. Nótese que las cosas, a pesar de constituir el mundo, no son el mundo. El mundo es algo más que ellas. Para esclarecer esto, recuérdese que Dilthey conoció la idea de mundo que profesaba Kant como idea reguladora; esto puede observarse, si bien de manera implícita y como trasfondo, en su texto "El progreso sobre Kant” (págs. 95-97 de esta misma obra). 
Obtenemos, pues, que la vida no parte de una primigenia contemplación del mundo, de la cual luego se aleja para crear su propio mundo, sino que está constantemente referida a él porque la vida está intrincada con el mundo. Esto es lo que nos dice Dilthey cuando expresa que "como siempre se halla presente el todo (del mundo) aunque sea como puro caos sensible (...) decimos: siempre es el mundo nada más que correlato del yo"23. El mundo y la vida constantemente se están refiriendo el uno al otro. Esto es lo que a su vez nos expresa también el profesor Cristin al decirnos que "Dilthey elabora una filosofía de la vida en la cual es fundamental la relación entre individuo y mundo" ${ }^{24}$. Es pertinente aclarar que si bien consideramos la vida como aquella unidad estructural que abarca en unidad el yo y el mundo, es acertado hablar de individuo y mundo, ya que es desde la conciencia individual desde la que cada uno se apercibe de la vida.

\section{Husserl y el mundo-de-la-vida}

Acabamos de hacer una pequeña exégesis de los planteamientos fundamentales de Dilthey respecto a la vida; ahora es el turno de Husserl. Recordemos que del apartado anterior hemos obtenido que la vida no se agota en lo que reflexiva y predicativamente se diga de ella.

Es sabido que el pensamiento de Husserl estuvo deambulando por varias vías, la cartesiana, la psicológica y la del mundo de la vida, que quizás sea la más influyente, atractiva y fructífera de todas por ser la final, la más compleja y la que mejor desarrolló su intuición de correlación hombremundo.
Según Eugenio Fink, como nos lo recuerda Cristin, el problema central de la fenomenología husserliana sería el problema del mundo ${ }^{25}$. Y es que es un problema fundamental porque la manera de salvar el sempiterno abismo entre realismo e idealismo que había disecado el pensamiento filosófico, era responder de manera contundente el problema del mundo, es decir, su existencia fuera de la conciencia, y su preeminencia sobre la misma. La gran intuición de Husserl, al considerar al mundo y al hombre como correlativos, le dio la gran ventaja de superar las ambivalencias propias del pensamiento moderno y antiguo así como de forjar un método propiamente filosófico. Sin embargo, lo subsumió en la paradoja de que el hombre sería sujeto y objeto del mundo, sin tener prioridad sobre éste porque el mundo y el hombre son correlativos. Esta paradoja forja y establece las relaciones del hombre con el mundo. Para Husserl, al igual que para Dilthey, la presencia del mundo exige ser creída, no es demostrada sino mostrada. Sin embargo, los afanes de Husserl de salvar la ciencia y crear un método estricto, además de su mentalidad matemática, no le permitieron dirigirse a los ámbitos de la cosmovisión, que incluso llegó a criticar. Para Husserl, la vida es la base de su filosofía; sin embargo, no es la vida la que crea su propio mundo como en Dilthey, sino que la vida vive un determinado mundo al que pertenece. La categoría de Lebenswelt (mundo de la vida) es la base final; final porque es el fundamento último que propone el último Husserl, de la correlación entre hombre y mundo. El mundo ya no es un mero conjunto del aparecer fenoménico de elementos que la conciencia debe sintetizar, como lo fue para Kant, ni tampoco es la res extensa del cartesianismo.

\footnotetext{
Dilthey, Teoría ...(1945) 17.

Cristin, Fenomenología ..., 78.

Cristin, Fenomenología ..., 72.
} 
El mundo ahora es mundo-de-la-vida, es una unidad vital que enmarca cada vida humana en un contexto preciso y determinado.

Pero Husserl reconoce aquel mundo natural que la ciencia que, en su tiranía, ha llegado a considerar como el único y verdadero ${ }^{26}$; estudia ese mundo regido por la causalidad bajo la espacialidad y la temporalidad, ese mundo fáctico que Husserl denominó Mundo uno, y sobre él instaura los diferentes mundos de la vida que se van erigiendo a través de las vivencias de los seres humanos; así pues, se habla del mundo de la cultura, el mundo de la política, el mundo de la cocina, el mundo de la universidad, etc. Estos mundos vitales no están regidos por la causalidad sino por la motivación ${ }^{27}$. Es en estos mundos vitales en los que vive el hombre.

Pero asumiendo la pregunta guía que nos motivó a estudiar los planteamientos de estos filósofos, preguntamos a Husserl por la manera como la vida en ese mundo-de-lavida fundamenta la verdad predicativa, es decir el conocimiento filosófico (en la clasificación de Husserl, a contraposición del natural). Resaltemos aquí las ideas fundamentales.

En primer lugar, el mundo, para Husserl, se nos da lingüísticamente interpretado, sea a través de la comunicación, de la tradición o del aprendizaje que implican estas dos. Y el hecho de que el mundo se nos dé mediado de esta manera implica algo que trabajó Dilthey durante toda su obra y es que la vida es histórica. El mundo de la vida está, pues, estructurado a partir de un criterio histórico que, al igual que en Dilthey, se trata de un "historismo" ${ }^{28}$ que parte del individuo mismo. El profesor Renato Cristin dedica todo el último capítulo de su mencionado libro a analizar El mundo de la vida como mundo histórico. La conclusión a la que llega aquí es que "Husserl ha querido mostrar el camino hacia una interpretación fenomenológica de la inclusión recíproca de mundo e historia”29.

Hasta aquí no hemos hecho más que llegar hasta la constitución del mundo de la vida como mundo histórico, lo cual apenas nos hace avanzar respecto a Dilthey. ¿Por qué es tan importante Husserl, entonces, en cuanto a la pregunta que nos concierne? La respuesta la obtendremos si nos detenemos en su texto Experiencia y juicio. No pretenderemos aquí desentrañar cada una de las ideas de este texto, sino que nos limitaremos, por razones de espacio y tema, a las consideraciones fundamentales de las temáticas tratadas en él. Husserl considera que toda verdad predicativa se basa en una verdad prepredicativa, que es el tema fundamental de nuestro trabajo. Husserl nos dirá que "la evidencia predicativa se funda en una evidencia pre-predicativa"30. recordemos que para Husserl 'evidencia' equivale a presencia, es decir que en todo conocimiento se anuncia ya el mundo, que constituye una especie de subsuelo en donde se asienta toda creencia que concierna al mismo (sea de carácter ontológico, epistemológico, etc.) ${ }^{31}$.

\footnotetext{
Husserl, Experiencia ..., 44-48.

Husserl, Experiencia .... Cf. Introducción del propio Husserl.

28 Respecto al tema del historismo, remitimos a la polémica que se puede plantear entre Julián Marías y Eugenio Imaz.

29 Cristin, Fenomenología ..., 72.

30 Daniel Herrera, “Heidegger: Prolongación, radicalización y abandono de la fenomenología de Husserl”, Escritos sobre fenomenología (Bogotá: USTA, 1986).

31 Eusebi Colomer, El pensamiento alemán: De Kant a Heidegger, vol. III (Barcelona: Herder, 1990) 394395.
} 
Por otro lado, Husserl considera que todo objeto tiene su manera propia de hacerse evidente, y que este horizonte en que todo objeto se manifiesta constituye el mundo en el que se asienta todo enunciado de sujeto y predicado de un juicio. "Esto es el mundo para Husserl. Este horizonte mundano es anterior a todo acto de conocimiento, puesto que todo acto de conocimiento lo presupone y pone en juego"32.

Es decir, la vida se sustenta sobre una base pre-predicativa, que también podríamos denominar como pre-reflexiva. Esta denominación no es en vano, ya que esta verdad es susceptible de ser predicativa, con las características esenciales que tiene esta verdad, como la de ser el fundamento del conocimiento, como lo determinó Kant apoyándose en Aristóteles: "El conocimiento se lleva a cabo en el juicio"33. O, en otros términos, todo conocimiento, todo saber filosófico o científico, con aspiraciones de generalidad y de universalidad, se fundamentan en una verdad pre-predicativa, en una vivencia que le sirve de fundamento. Digámoslo con el profesor Daniel Herrera: "esta verdad prepredicativa podemos llevarla al nivel de la predicación, gracias a esa otra vivencia que nos es dado tener, a saber la reflexión”34.

Y bien, ¿qué concluimos, entonces? Recordemos que con Dilthey habíamos encontrado que el conocimiento no agota la vida, que la visión del mundo es más que lo que se puede comprender con la razón a partir de ella. Con Husserl hemos recordado el elemento histórico del mundo-de-la-vida, reconociendo que bajo toda verdad predicativa, bajo todo conocimiento, subyace el flujo de las vivencias pre-reflexivas, el horizonte del mundo pre-predicativo que enmarca un cierto juicio de conocimiento en un contexto, como un enunciado real que pronuncia una persona concreta. Las relaciones entre Weltanschauung y Lebenswelt empiezan a manifestarse. La vida crea un mundo, y ahora hay un mundo-de-la-vida, un mundo de carácter vital que se asume bajo una determinada concepción. No se malinterprete lo dicho aquí: simplemente estamos estableciendo los nexos precisos entre las categorías fundamentales de ambos filósofos alemanes con la intención de dilucidar una respuesta a nuestro interrogante; respuesta que ya sentimos cerca.

\section{Un aporte personal}

Del anterior análisis se infiere que la existencia del mundo de la vida implica que el mundo no lo sea de cosas, sino uno en que se vive, porque el mundo tiene un carácter vital y circunstancial, definido por el individuo para quien es el mundo ${ }^{35}$. También es preciso recordar, con Dilthey, que el mundo en sí mismo no es contradictorio, que si llega a serlo se debe a la diferencia de imágenes, percepciones y concepciones que se tienen de él:

Las contradicciones entre los sistemas radican en su pluralidad de aspectos de la vida, que se expresa en las formas capitales de aquellos. De nuevo la contradicción se halla, tan solo, en las imágenes científicas del mundo objetivamente independizadas; pero si se consideran las formas capitales como

\footnotetext{
Colomer, El pensamiento ..., 394-395.

Citado en Cristin, Fenomenología ..., 67.

34 Daniel Herrera, “Qué es fenomenología”, La persona y el mundo de la experiencia (Bogotá: Universidad San Buenaventura, 2002) 14.

35 Dilthey, Teoría ...(1994) 41 (nota 6).
} 
expresiones relativas de los diversos aspectos de la vida, entonces tenemos, en estos aspectos, una diversidad pero no una contradicción ${ }^{36}$.

$\mathrm{Y}$ es de esta manera que, siendo el mundo uno (recordemos a Husserl), los diferentes mundos de la vida divergen. De esta manera se evidencia que los problemas que se manifiestan a través de las grandes preguntas del filosofar y de la reflexión humana no dependen de la presencia del mundo como de la vivencia de la propia vida en ese mundo. Es decir, entre yo y el mundo no sólo existen conexiones causales, sino que también se establecen, desde mí, relaciones vitales. El mundo es, pues, ese correlato del yo, es lo otro del hombre ${ }^{37}$.

La vida se da en el mundo, pero el mundo cobra significado en la vida, luego aparece en la vida con todo su significado; o sea, me entero del mundo en mi vida. Pero el mundo no me viene con un sentido predeterminado, sino que se me presenta sencillamente como lo exterior, a veces en sensibilidad caótica susceptible de traducirse en una intelección ordenada. El ser humano, tal y como lo vieron los existencialistas, se halla en el mundo, es un ser-en-el-mundo, arrojado, es decir, expuesto a la posibilidad, y a la conciencia ante la posibilidad de la posibilidad, como Kierkegaard definiría la angustia. El ser humano no está hecho, fijado y terminado, sino que se hace con sus acciones, $y$, por carecer de una "naturaleza", se ve precisado a elaborarla al precio de su propia existencia.

El hombre nace, crece, descansa y se levanta, y el mundo continúa su marcha. Un mundo que parece ser regido por leyes que las diversas ciencias tratan de extraer de las mis- teriosas entrañas de ese mundo; así mismo, el hombre se da cuenta que esa ciencia, que se supone aclara y explica el mundo, no está siquiera acabada ni esbozada de manera absoluta. Las ciencias, como las filosofías, se superponen, refutándose entre sí, con experimentos fallidos y grandes hallazgos, pero incapaces de formular sistemáticamente la (o por lo menos una) explicación del mundo. En la ciencia se trata de un mundo físico en el que rigen las llamadas leyes naturales. Es un mundo en el que sale el sol y el tiempo pasa, es un mundo en el que se dice que el sol no sale porque es la tierra la que se mueve y que el tiempo es una unidad con el espacio. Sin embargo, tras este mundo, y como perteneciente al mismo mundo, aparece una esfera totalmente diferente que consiste en una dimensión vital, la cual cambia las percepciones de los fenómenos de la naturaleza, a pesar de ser los mismos fenómenos. Los distintos individuos que los perciben lo hacen de diversas maneras, según sus prejuicios, sus personalidades, maneras de ser y pensar. Es un mundo que, a pesar de ser el mismo que el anterior, aparece como complemento y a la vez contradictor del mundo físico: es el mundo vital, es el mundo-de-lavida que nos ha mencionado Husserl.

El mundo es, por definición cotidiana, una unidad que encierra un conjunto; así, el hombre vive físicamente en la esfera vital del mundo y vitalmente en su esfera física. La vida se compenetra en el mundo en una trabazón que no permite separarla efectivamente, mas sí formalmente. Así, las diferentes percepciones varían desde la perspectiva que se les mire: el color azul puede ser el color del cielo, o una simple frecuencia de onda, o el color que representa los océanos en la ban-

Dilthey, Teoría ...(1945) 9.

37 A manera de acotación digamos que ha quedado plasmada la metodología de Dilthey que consiste en un conocimiento de sí (autognosis), luego en una interpretación de la vida ajena (hermenéutica) y finalmente en el conocimiento de la naturaleza. Cf. Introducción de Julián Marías en Dilthey, Teoría ... (1994) 30. Sin embargo, esto es simplemente una nota al margen para facilitar la intelección y como ayuda informativa. 
dera de Colombia, o quizás la simbolización de la apacibilidad o la tristeza para algún artista; depende de lo que Ortega y Gasset ha llamado perspectiva, que, consideramos, es una síntesis de las categorías de Weltanschauung y Lebenswelt.

Las "cosas" adquieren diversos sentidos, infinidad de significaciones cuyo ejemplo más evidente se encuentra en los diversos casos semánticos en las lenguas. Lo vital se esparce por lo físico y éste tiene su significado en lo vital. El mundo es, pues, una gran cantidad de conductos capilares por los que continuamente se están comunicando las esferas físicas del mundo y las vitales que los hombres hacen de ese mundo. La unidad del mundo la podemos ver en la ciencia; la diversidad del mismo, en la poesía. El mundo se funda, pues, en una serie de creencias, el mundo es un constructo en cuanto concepto, pero es una creencia en cuanto realidad. Desde los inicios de la humanidad, el hombre ha querido comprender qué es eso del mundo, aquello que no es él, lo exterior a él. Los primeros cultos animistas y fetichistas lo vieron todo plagado de espíritus y personificaban toda la naturaleza; posteriormente se forjaron, de una manera más definida, los mitos que esclarecían la naturaleza de los sucesos, mas no los explicaban; luego devino la filosofía, que siempre ha tenido pretensiones de explicar en términos de universalidad y necesidad, aunque a lo largo de la historia pocas veces ha conocido tal gloria porque el mundo gira constantemente, el cambio está al acecho; a mitad de camino aparecieron las grandes religiones que acuñaron el feliz nombre de creación, dejando así de lado el asunto del mundo para preocuparse por el del autor del mundo. Luego vinieron grandes cambios culturales, el Renacimiento y la Reforma, y la manera como en Occidente se empezó a ver el mundo cambiaría decisivamente; ya el mundo no era la sagrada creación de Dios, sino que consistía en simples medios de producción o fenómenos regidos por leyes. Con Kant, en la Ilustración, la consideración del mundo fue entendida como una idea reguladora, como una herramienta mental que captura todo ese desorden que aparece ante la sensibilidad. Tras Kant llegaron los idealistas y los románticos propugnando la unidad del mundo con una hipóstasis formada por la filosofía, denominada espíritu, y que es difícil precisar con exactitud lo que pueda ser aunque usualmente se define, de una manera harto deficiente, como lo contrapuesto a lo físico y sensible. Ha habido quienes han negado el mundo, otros sólo su realidad exterior, otros lo han reducido a la realidad mental (representaciones) que de él tenemos. El mundo ha sido considerado de muy diversas maneras a lo largo de los tiempos; en la actualidad existen corrientes que consideran el mundo como un gran ser viviente, otras simplemente como una amalgama de materia y energía, otras como cuerdas en vibración, otras como vida, las hay que lo hacen como razón, etc. Sin embargo el mundo es el mismo: las opiniones son contradictorias, pero el mundo permanece igual. Ese era el desespero del Sabio al expresar que todo es vanidad porque no hay nada nuevo bajo el sol ${ }^{38}$.

El hombre ha fundado lo que cree que es el mundo en sus creencias; así, pues, no puede llegar a saber qué es el mundo, porque lo máximo que logra es llegar a creer qué es el mundo, y ese creer asume las mismas leyes naturales, puesto que la razón en las que están fundadas se asienta en una creencia. Recordemos cómo Ortega y Gasset, en el primer capítulo de Historia como sistema, nos señala la manera como la vida trabaja con

38 Ec 1, 1-11. 
las creencias ${ }^{39}$. En la creencia de que esa razón pueda ser valedera. El mayor instrumento del hombre para la intelección del mundo, la razón, posee supuestos que no puede explicar. En la razón misma encontramos un abismo de irracionalidad. ¿Cómo salvarlo? Las necesidades vitales del hombre exigen que sea solucionado el paso de tales abismos.

El hombre configura el mundo a partir de creencias, como lo vimos más arriba con Dilthey y Husserl, procedimiento que se ha visto denigrado por ciertas corrientes cientificistas debido a que lo consideran irracional y a que califican las creencias como ideologías al servicio de la manipulación. Sin embargo, el mundo, como "constructo" vital, es una serie de creencias que, como bien lo expresaba Ortega y Gasset en su mencionado texto, no tienen una relación lógica sino vital. Así, la fe en un Dios providente es tan válida como la fe en la razón físico-matemática, o como la fe en el progreso. El hombre necesita de creencias que le articulen el mundo racional con el vital. Dichas creencias pueden entenderse de dos maneras: unas creencias vivas que impulsan al individuo a la acción, que sirven de motores para la vida porque producen inspiración, y otras creencias que son muertas porque, aun cuando se poseen, no tienen eficacia ni influencia alguna en la vida propia. Así, nuestras creencias, "más que tenerlas, las somos" ${ }^{40}$. De esta manera, el mundo presenta su ambivalencia; siendo uno mismo, se presta para diversas intelecciones, dando pie a diversas concepciones del mundo, a diferentes maneras de vivirlo, a muchos mundos-de-la-vida. Que- rer acapararlo todo en un sistema filosófico es no haber entendido lo que realmente el mundo significa: recordemos que "el conocimiento no agota lo real”, y no lo agota porque lo real no puede ser solamente conocido, lo real implica vivirlo, sufrirlo e incluso ignorarlo. Sólo en este sentido lo real se considera como tal. Así, pues, y en este sentido, no todo lo real es racional, o, si se prefiere, en términos menos drásticos pero igual de expresivos, “el orden y conexión de las cosas del mundo de la vida no coincide plenamente con el orden y conexión de nuestras ideas, de nuestros pensamientos, de nuestra razón”41.

Pero procedamos a analizar desde un punto de vista más positivo las relaciones entre vida y mundo, dos conceptos que quizás hasta aquí hemos mencionado como si fuesen absolutamente opuestos. No hacemos retracción de lo dicho hasta aquí, sino que sencillamente hemos de formular una afirmación, una premisa que nos facilite continuar con nuestro desarrollo. De esta manera, empecemos escuchando a Dilthey al respecto: "Siempre es el mundo nada más que correlato del yo" ${ }^{42}$, afirmación que es similar a la intuición de Husserl. La existencia del yo implica la presencia del mundo. Esta es la premisa de la superación del idealismo que tanto se le ha alabado a Husserl y que poco se ha estudiado en Dilthey. Esta premisa establece un nexo entre el hombre y el mundo que revalora la importancia de ambos elementos de la relación, pero que no supedita ninguno al otro. Así, el hombre no puede existir sin mundo, y el mundo a su vez nece-

\footnotetext{
39 José Ortega y Gasset. Historia como sistema, Obras completas, vol. VI (Madrid: Alianza/Revista de Occidente, 1983) cap. 1.

40 Ortega y Gasset, Historia ..., cap. 1-2.

${ }_{41}$ Disponible en: <http://www.e-torredebabel.com/Historia-de-la-filosofia/Filosofiacontemporanea/Ortega/ RazonVital.htm>

42 Dilthey, Teoría ...(1945) 17.
} 
sita del hombre. Esto es lo que Ortega considera como el ser indigente ${ }^{43}$. La conexión entre sujeto y objeto en un todo llamado vivencia, implica que no hay independencia de las partes: el sujeto sin objeto sería un sujeto ideal, como de hecho era el del idealismo, y un objeto sin sujeto es eso, un objeto, una cosa entre las cosas, sin significado. Pero el mundo, lo que se denomina tal y no simplemente "cosa", es mucho más que un conjunto de cosas fijas, predeterminadas y estáticas. Evidentemente, lo que se considera como mundo (exterior) puede no variar, pero mi mundo sí (que estrictamente es el verdadero significado del término mundo, ya que el mundo como tal no existe, el mundo es, como decíamos, un constructo y una creencia con que el hombre interpreta eso que está fuera de él). Así, pues, "todo lo que el hombre puede ver en el mundo es siempre la relación, la trama de su vida con las propiedades de aquél, que no puede cambiar" ${ }^{\prime 4}$. Detengámonos en lo primero de esta cita: el hombre, al relacionarse con su entorno, al ejercitar conscientemente la correlación con el mundo, al enterarse de sí y del mundo, lo que hace es radicar todas las vivencias en su propia realidad, es decir, en la vida misma. El hombre no puede ir más allá de la vida misma, ya lo decíamos, pero lo importante de esto es considerar no sólo lo que está en la vida, sino lo que se queda por fuera, y eso que se queda afuera, tras la vida del hombre de la que él mismo no puede salir, es el conocimiento de las cosas por sí mismas en una absoluta objetividad. Ya lo decíamos: una vivencia determina a las otras, tanto a las pasadas como a las del porvenir. No es, pues, posible hacer tabula rasa de lo vivido y tra- tar de conocer algo en sí mismo, primero porque no podemos salirnos de nuestra realidad que es la vida, y segundo porque en la medida en que lo conozco se hace un conocimiento mío, no puedo establecer identidad con el objeto, sino que siempre están presentes las relaciones y las tramas de mi vida con eso que hay en el exterior. Retomemos la cita en su segunda parte: relación (...) que no puede cambiar. No puede cambiar esa relación porque, como bien explica Ortega, "cabe renunciar a la vida, pero si se vive no cabe elegir el mundo en que se vive”45.

Es decir, a diferencia de lo que se hacía en el Renacimiento, en el que se pensaban y se configuraban utopías (Moro, Campanella, Bacon), las utopías no se piensan sino que se hacen. Bien lo decía Marx en la undécima tesis sobre Feuerbach: "Los filósofos se han limitado a interpretar el mundo de distintos modos; de lo que se trata es de transformarlo" ${ }^{* 6}$. Sin embargo, valga la aclaración, antes de transformar el mundo es preciso haberlo comprendido, esto es, haberlo interpretado, asimilado, apropiado. Antes de transformar predicativamente el mundo, es preciso haberlo vivido pre-predicativamente. Podré transformar el mundo cuando sea $\mathrm{mi}$ mundo, porque es bien cierto que "la filosofía tiene como función hacer posible una acción autónoma con conciencia de su finalidad" $^{47}$. De esta manera puede o no gustarnos el mundo, parecernos absurdo o fantástico, sin embargo es ese mundo el que se nos presenta y que exige, por ser indigente, como nosotros, ser interpretado, conocido y apropiado.

\footnotetext{
43 Cf. José Ortega y Gasset, ¿Qué es filosofía?, Obras completas, vol. VII (Madrid: Alianza/Revista de Occidente, 1983) 410.

44 Dilthey, Teoría ...(1945) 28.

45 Cf. Ortega y Gasset, ¿Qué es filosofía?, 417.

46 Karl Marx, Tesis sobre Feuerbach y otros escritos (México: Grijalbo, 1970).

47 Wilhelm Dilthey, “Qué es filosofía”, Teoría ...(1994) 113. El subrayado es mío.
} 
Para efectos explicativos, quizás sea más comprensible el uso de un término que es propio de Ortega: el de circunstancia. El mundo es esa circunstancia, y vivir "es convivir con una circunstancia" ${ }^{38}$. El mundo es, pues, una serie de circunstancias que al vivir nos encontramos, algunas de las cuales nos presentan facilidades para desenvolver cierto sentido de nuestra vida, otras dificultades. En el mundo se encuentran circunstancias agradables y desagradables, oportunas e inoportunas, benévolas y dañinas. Esto decía Epícteto al enunciar que "No son las cosas las que afectan a los hombres sino las opiniones que se tienen de ellas"49. Este esclavo liberado y estoico tenía otra intención al enunciar tales expresiones, pues él buscaba la ataraxia propia del sabio, mas para nosotros es pertinente en el sentido con que la estamos remantizando, que fundamentalmente implica que el mundo no se configura ya por cosas, como en el realismo, ni por meros pensamientos como en el idealismo, sino de acuerdo a cómo nos afectan dichas cosas, es decir, a partir de contenidos vitales. "Lo importante no es que las cosas sean o no cuerpos, sino que nos afectan, nos interesan, nos acarician nos amenazan y nos atormentan (...) Mundo es sensu stricto lo que nos afecta" ${ }^{50}$.

Hemos estado dejando de lado un aspecto fundamental que ni siquiera hemos nombrado: si el mundo se expresa en términos de un mundo vital, porque el hombre configura el mundo a partir de su vida, es preciso explicar cómo se da dicha configuración. Las cosas, como acabamos de ver, tienen realidad vital (a pesar de las explicaciones, agregamos el término 'vital' para evitar confusiones) en la medida en que aparecen y las des- cubro en mi vida. Pero, ¿cómo aparecen? En sí mismas no las puedo conocer porque no puedo salir de mi propia vida y tampoco son yo, por lo que tampoco mediante una comunión de identidad pueden hacerlo. La respuesta es bastante sencilla, pero no por eso irrelevante: "la forma de nuestra captación es siempre lo interior que se manifiesta en lo exterior: por eso vivimos siempre en símbo$\operatorname{los}{ }^{51}$. En este sentido, la vida se capta como mundo, es decir, se toma conciencia de la vida siempre bajo un parámetro de exteriorización. Nuestro interior (la vida misma) se exterioriza. ¿Hacia dónde? Hacia el mundo exterior, y lo transforma en mundo vital, pero dicha transformación depende siempre de una actividad simbólica (recordemos aquí lo dicho al inicio del ensayo en el aparte titulado "El mundo"). Aquí tiene cabida la definición de Cassirer del hombre como un animal simbólico, y la versión heideggeriana del zoon logon, traducido como "animal dotado de palabra”, aceptando la definición que Saussure da del lenguaje, a saber: la facultad inherentemente humana de construir y manejar conductas simbólicas. Así, pues, la apropiación del mundo puede darse en términos del lenguaje, sea éste artístico, científico, literario, pictórico u otro. Recordemos lo referente a la manera como el mundo se da lingüísticamente interpretado, según veíamos en Husserl.

A manera de acotación final, hemos de reconocer una visión que hace Ortega y que es pertinente para la coherencia del discurso que hemos estado desarrollando. Acabamos de mencionar, hace dos párrafos, que las cosas entran en nuestra vida en la medida en que nos afectan, pero para efectos de rigor de lenguaje filosófico, sería más pertinente hablar

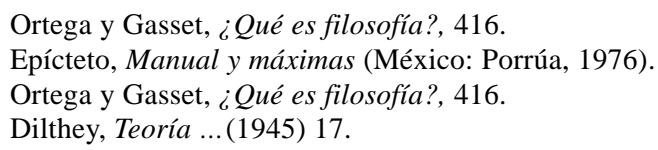


de “importancias” en lugar de hablar de “cosas”, pues este último término posee demasiadas connotaciones naturalistas y puede conducir a equívocos y a malos entendidos si se usa para determinar cualquier contenido vital, porque una circunstancia no se configura de cosas sino de importancias, según nos recuerda el profesor Garagorri ${ }^{52}$. Si queremos, pues, definir suscintamente lo dicho respecto al mundo en relación con la vida, diremos que "Mundo es lo que hallo frente a mí y en mi derredor cuando me hallo a mí mismo, lo que para mí existe y sobre mí actúa patentemente"53. Considero que con esto quedan terminadas mis reflexiones sobre cómo la vivencia del mundo pre-predicativo fundamenta el tipo de conocimiento predicativo, y la manera como pueden establecerse unos nexos, si bien primarios y que es preciso profundizar, entre las categorías de Weltanschauung y Lebenswelt.

52 Cf. Paulino Garagorri, Unamuno y Ortega (Navarra: Salvat/Alianza, 1972) 33. Si se quiere un estudio más minucioso respecto a la relevancia tanto conceptual como vital que desarrolla la noción de "cosa” en la actualidad, remitimos al texto de Julián Marías Razón de la filosofía (Madrid: Alianza, 1993) 45 y ss.

53 Ortega y Gasset, ¿Qué es filosofía?, 425. 